\title{
Paediatric illness and care: more than just feeling poorly
}

\author{
Rebecca Black $^{\text {a, c }}$, Jeni Harden ${ }^{\mathrm{b} *}$, and Richard Chin ${ }^{\mathrm{a}, \mathrm{c}, \mathrm{d}}$ \\ ${ }^{a}$ Muir Maxwell Epilepsy Centre, University of Edinburgh \\ ${ }^{\mathrm{b}}$ Usher Institute of Population Health Sciences and Informatics, University of Edinburgh \\ Child Life and Health, University of Edinburgh \\ ${ }^{\mathrm{d}}$ Royal Hospital for Sick Children, Edinburgh, UK \\ *Corresponding Author at: Jeni.Harden@ed.ac.uk
}

\section{Abstract}

The medical education curriculum in the UK includes a component on understanding and appreciating the psychosocial aspects of illness and care. Yet, children's own experiences of illness and care are often overlooked. This article explores these neglected experiences and insights through an examination of paediatric epilepsy. The psychosocial implications of being diagnosed and living with epilepsy for children and their families are wide ranging, affecting physical and emotional wellbeing and involvement in everyday activities as well as being burdensome to manage and treat. As such, children and their families have to utilize various coping strategies in order to incorporate epilepsy into their lives. Obtaining and appreciating children's own experiences and perspectives can highlight key challenges for healthcare professionals working with these patients and their families, including recognizing children's autonomy, effective communication with them, and acknowledging the wider context of children's lives.

\section{INTRODUCTION}

Illness and care do not occur in isolation - both are influenced by a range of social and psychological factors. Understanding these dimensions of illness and care is a core proponent of medical education in the UK. ${ }^{1}$ This is reflected in the design of the medical curriculum, which expressly aims to ensure that graduates have the skills to identify and understand the impact of societal and behavioural factors that contribute to illness or can impede treatment success. ${ }^{1,2}$ Despite this laudable aim, there is often not enough time or space given to allow students an in-depth exploration of these influential factors. ${ }^{3}$ In particular, children's own experiences of illness and care are not often represented in the curriculum.
This neglect is also sadly reflected in wider social science and clinical research. ${ }^{4}$ Research has previously focused on parental reports of children's illnesses, using these as the lens through which to explore the impact illness has had on their child's life. ${ }^{5}$ Although this perspective has value, recent literature in this area has suggested that obtaining children's own experiences and accounts of illness and care provides much richer insights. ${ }^{6}$ This acknowledgement of the value of seeking children's perspectives directly reflects a broader shift in our recognition of children's ability to understand and articulate their experiences and their right to be heard. ${ }^{7}$ This shift has primarily been driven by the introduction of the United Nations Conventions on the Rights of the Child ${ }^{8}$ and, more recently, the increasing focus on the child directly as the primary service user in the field of paediatrics. 
This article aims to build upon this by exploring how children experience illness and its associated psychosocial impacts, focusing specifically on paediatric epilepsy, a chronic condition that is often diagnosed in childhood. Epilepsy is a complex condition that is considered a spectrum disorder, and carries with it a high risk of comorbidities. ${ }^{9}$ Consequently, a diagnosis of epilepsy holds a variety of implications for a child's life beyond the physical effects associated with seizures. ${ }^{10}$ The primary goal in contemporary epilepsy management and treatment is therefore to optimize the child's life in order to give them a lifestyle that is as free as possible from not only the medical but also the psychosocial effects of their condition. ${ }^{11}$ This makes it an ideal example through which to explore the broader topic of children's experience of illness.

This article begins with a brief exploration of the similarities and differences between child and adult patients in terms of psychosocial implications of illness and care. This is followed by an examination of the psychosocial impacts of epilepsy on children, before moving on to explore children's own accounts of coping with illness, including the role their immediate family has within the coping process. In the final section, a discussion of the challenges facing medical professionals as they engage with children in a healthcare context will be presented.

\section{Children and adults: different?}

Illness can have different clinical presentations in children and adults, and both groups will also respond differently to treatment. Similarly, the psychosocial impacts of illness will influence them in differing manners. Childhood and adolescence are stages of life characterized by rapid and extensive physical, social, emotional, and cognitive development. ${ }^{12}$ How children experience illness is inevitably shaped by their stage in life, the degree to which they are able to understand and/or accept their illness and associated care, their interactions with adults, the meaning of illness in their lives, and what they prioritize as significant and important. ${ }^{4,7}$ Put simply, the differences between children and adults developmentally will shape the psychosocial impact of illness and care. It is important to understand these differences and the resulting challenges when providing care for young patients.

\section{Psychosocial impacts of illness: children with epilepsy}

Research has identified that epilepsy can have a significant physical, emotional, and social impact on children's lives. It is also not uncommon for other neurological (e.g. autistic spectrum disorder) and nonneurological problems (e.g. gastroesophageal reflux) to coexist with epilepsy. ${ }^{12,13}$

\section{Physical and emotional impact}

Repeated seizures can have a direct impact on children's health and wellbeing including physical injuries, muscular pains, headaches, tiredness and general lack of energy, and the need for more sleep than normal. ${ }^{14,15}$ The side effects of antiepileptic medication can also have ramifications for children. These can be physical - such as weight gain, stomach aches, and headaches - and emotional, such as mood changes. ${ }^{6,17}$

Unlike many adults, children may not be able to fully articulate or realize the true nature of these physical and emotional changes to their bodies. For example, children have reported that antiepileptic medication can make them "feel bad" in a general sense., 16 Healthcare professionals must therefore be alert to this and understand that "feeling bad" is a justifiable side effect of epilepsy and may allude to other underlying issues. Although these physical and physiological implications of having epilepsy cannot always be entirely reduced or mitigated, an understanding of how they affect children's lives is vital to helping them live as freely as possible from the effects of their condition. This also provides an opportunity to help children better understand their condition by helping them 
explore why they "feel bad" and identify the specific causes of this feeling.

Children with epilepsy often report a range of negative emotions in relation to their condition. These include feeling troubled, sad, or occasionally depressed, and experiencing frustration or anger at issues such as having seizures, medication, and the accompanying side effects. ${ }^{17}$ Feelings of fear, including that of death, have also been reported by some children in the context of what happens to them in a seizure. ${ }^{18}$ When describing social relations, children report feeling lonely or isolated, and being embarrassed about being seen having a seizure. ${ }^{16}$ Nevertheless, children also report positive emotions relating to their epilepsy, including having a sense of pride in coping with epilepsy and feeling special. ${ }^{18}$ These emotional and mental health symptoms are often overlooked or undiagnosed, and hence go untreated. ${ }^{18,19}$ This is because such symptoms are primarily mistaken to be a result of seizure activity. ${ }^{19,20}$ Therefore, an awareness of such problems that children may be experiencing but are unable to fully articulate or understand will be useful in helping healthcare, education, and social care professionals identify and mitigate potential concerns while strengthening positive coping mechanisms.

However, paediatric epilepsy does not only affect a child's life, it also has ramifications for their parents, siblings, and wider family networks. Parents of children with epilepsy often describe feeling burnt out and exhausted from worry, and report that the constant (perceived) need to monitor their child's physical and mental health is draining. This can be exacerbated by the challenge of acting as their child's advocate in healthcare and education contexts. ${ }^{15}$ Siblings have also reported feeling anxious, sad, worried, and lonely or isolated in their own right. ${ }^{6}$
Impact on involvement in everyday activities and social relations

Beyond the direct effects on physical and emotional wellbeing, having epilepsy can also influence children's involvement in everyday activities. Children often report limitations in their participation in social activities and education because of their epilepsy. ${ }^{15,16}$ The specific activities that children and young people have expressed frustration about not being involved in changes with age. While missing sleepovers and interrupting play with friends to take medication were significant concerns for younger children, ${ }^{20}$ older children were more concerned with the consequences of going to nightclubs or drinking alcohol, and whether they will be able to drive. ${ }^{16}$ These varied limitations may mean, or at least make them feel, that they are treated differently from their peers, causing them stress and anxiety.

Some restrictions on what children can do in their everyday lives come from suggestions by healthcare professionals intended to minimize risk to the child, for example taking baths alone. Parents and teachers also attempt to limit the risk of injury or harm by restricting a child's involvement in everyday activities, for example, not allowing young children to play with friends outside. ${ }^{15,16}$ In addition, children have also described holding themselves back from engaging in social and everyday activities because of a lack of selfconfidence. ${ }^{16}$ This can create a profound impact on children's emerging and developing autonomy. ${ }^{17}$ Keeping epileptic children safe from harm while allowing them freedom to behave like other children is clearly a challenging balancing act. Healthcare professionals play an important role in ensuring that this balance is struck through conversations with children and their parents.

This balance is also particularly paramount as the theme of "being normal" is striking in many accounts of children's own experiences of epilepsy. Children with epilepsy describe being "normal" as vitally 
important, yet many report feeling different and that they do not belong. ${ }^{17}$ Many studies have widely documented that children with epilepsy experience difficulties in making friends and are bullied and stigmatized, hence affecting their social development ${ }^{2}$ Moreover, the need to take medication serves as a constant reminder of their differences, resulting in potential issues of non-adherence to medication regimes in later life. ${ }^{18}$

Children's differing competencies and levels of understanding may preclude them from talking about the problems they are facing or from being able to articulate that something is wrong. Being aware of these potential impacts of living with epilepsy from a child's perspective may contribute to earlier interventions and support where required. It is important, for example, to note that stress and anxiety are commonly associated with depression, and that adult problems often have antecedents in childhood. Poorer socioeconomic outcomes and early deaths in adulthood following childhood-onset epilepsy are also associated with poor mental health in childhood. ${ }^{22,23}$ Consequently, great care and attention should be given to identifying and addressing stress and anxiety in its early stages.

\section{Coping with illness}

Given the psychosocial impacts of illness and care, it is important to understand how children and families cope with epilepsy. This can facilitate the development of supportive interventions that will enhance acceptance of the illness and ultimately assist in the coping process. ${ }^{12}$ In this article, "coping" refers to both the practical response to illness and the cognitive strategies by which individuals give meaning and come to terms with their altered situation and body. ${ }^{24,25}$

The accounts of children with epilepsy have consistently emphasized the importance of emotional and practical support from their parents and siblings, such as helping them through seizures and being there afterwards to ensure that they are feeling fine. 6 In addition, parents support and assist children by reminding them to take their medications day and night, with the hope that it will also prevent seizures. ${ }^{15,21}$ Other practical coping mechanisms supported by families include strategies to prevent seizures, such as maintaining regular sleeping patterns, limiting trigger activities, and being aware of auras. ${ }^{15,21}$ Support from close family members can help children adapt to the changes that being diagnosed and living with epilepsy brings. ${ }^{15,26}$

It is important, however, not to assume that parents and children cope with illness in the same way or that they need the same support. For example, parents emphasize the importance of learning about epilepsy as it helps them to cope with their new care-giving responsibilities. ${ }^{15,27}$ Healthcare professionals can easily facilitate this learning by providing suitable resources. On the other hand, more information or knowledge about epilepsy is less vital to children and, for some, may even be unwanted. ${ }^{15}$ This difference between children and parents needs to be managed delicately. Given the intertwined nature of coping, it is important to ensure that parents and siblings are able to cope effectively as this will boost the child's ability to cope themselves. $^{12}$

As noted above, coping also has a cognitive dimension that relates to how illness is given meaning. After a diagnosis of epilepsy, children and parents can crave the "normal" life that existed before. ${ }^{28}$ Although a "normal" life is potentially achievable with appropriate treatment and management of the condition, it is part of the coping process for parents in particular to mourn the "old normal" and the childhood that their children could have had.

The presence of a chronic illness creates a new sense of normality; children and their families generally make adaptations and compromises in their lives to accommodate it. ${ }^{27}$ Roles and routines change as the 
management of the condition gets absorbed into everyday family life. For example, parents often refer to the process of reframing the parental role to include more of a carer role. ${ }^{28}$ Similarly, medication regimes will form part of a new routine for everyday family life. ${ }^{29}$ It is important to note, however, that children are not passive in this process; they actively participate in creating this new "normal" as they accommodate the condition and should be supported in doing so. ${ }^{7}$ For example, many children with epilepsy choose not to disclose their diagnosis to peers and friends to maintain their "normality". ${ }^{16}$ Appreciating these wider impacts of epilepsy allows for a better appreciation of how children and their families begin to understand and cope with the condition now being part of their lives.

\section{Challenges of paediatric care}

Differing capabilities, life experiences, maturity levels, and the wider context of family can all prove challenging for healthcare professionals as they seek to treat and manage childhood illness.

\section{Recognizing children's agency and autonomy}

A great deal of medical research and clinical practice on childhood illness has operated on the basis that children under the age of 12 years are not seen as capable of taking on responsibilities of or being actively involved in their own chronic illness. ${ }^{30,31}$ It is only at the point of adolescence that children, or young people, are seen as being able to begin taking charge of their own care. ${ }^{32}$ It is unsurprising then that decisions around participation and agency are usually mitigated by the child's chronological age and maturity. ${ }^{33}$

However, children have shown the capacity for a strong practical understanding of their condition. They see themselves as key contributors to their own care and appreciate adults engaging with them in ways that acknowledge this. ${ }^{32}$ Alderson and colleagues ${ }^{32}$ demonstrated that from as young as 4 years of age, children start to understand the principles of the diagnosis of diabetes and make responsible decisions regarding management. Their competence to consent was developed through their experience rather than age. Furthermore, children demonstrated and enacted their agency - as social agents making choices and taking responsibilities in conjunction with those around them. ${ }^{4,33}$ It is therefore important that children's contributions in healthcare discussions should be recognized as valuable and reliable, ${ }^{31}$ and that paediatric healthcare professionals should acknowledge children's agency and autonomy through their conversations and in the decision-making process, instead of deciding this solely based on a child's age.

\section{Developing effective communication}

Our society is structured around a generational hierarchy that results in a power imbalance between children and adults. Inevitably, this will shape expectations of the adults (parents and healthcare professionals) and the children involved in a healthcare setting. Skilful communication is therefore required to facilitate children's meaningful participation in their care. This includes the following: being mindful of different capacities and priorities of children, taking care not to be patronizing, describing why their views are being sought, and how this situation might be different from what happens in other contexts, for example in school. Offering children alternative ways to communicate and participate, or simply to help them feel at ease during an appointment, can also allow them to set the style of conversation engagements. How children prefer to communicate and participate may change as the child becomes more confident, and certainly as they become older, so it is useful to do periodic checks on whether the child is happy with the process and styles of communication. ${ }^{32,33}$

\section{Acknowledging wider contexts of children's lives}

As highlighted above, it is important to appreciate that children are generally not experiencing their illness alone. Parents and healthcare professionals hold key roles in a child's life, particularly in the context of 
illness. ${ }^{5,34}$ They are both facilitators and restrictors to a child's agency, often making decisions as to whether the child is "able" or "capable" to participate in discussions and to what extent and form this participation takes. ${ }^{5}$

LeFrancois ${ }^{35}$ highlighted that the connection of this with age and competency is particularly acute when children actively take responsibility for their health and medication in a manner that differs from their parents' perspective. According to LeFrancois, when such views differ, parents are likely to elicit a protectionist response and deem their children as both vulnerable ("too young") and incompetent ("immature") by virtue of their status as a child with a chronic illness. ${ }^{35}$ The connection of chronological age and maturity with competence, and correspondingly with agency, can lead to children appearing passive with no role to play in their own illness and care. ${ }^{36}$ It is important that healthcare professionals do all they can to ensure that children are provided ample opportunities to exercise their agency through effective communication. ${ }^{5}$ Furthermore, parents themselves may also need more information and support, which can potentially result in them dominating the discussions. Opportunities for parents to discuss concerns with healthcare professionals independently may also be valuable, such that time spent with the children will be focused on them and their needs.

Coyne $^{34}$ illustrated that children's emerging autonomy needs to be fostered by both parents and medical professionals. Both have a significant influence on whether a child's efforts to participate are supported. ${ }^{38}$ Being aware of interactions and ensuring that parents do not dominate or dismiss children's views and opinions is important for effective communication and, in turn, for recognizing children's autonomy. ${ }^{5}$

\section{CONCLUSION}

This article sought to draw attention to children's experiences of illness and care using the example of paediatric epilepsy, where the impacts of the condition are wide ranging and entrenched. Although the issues discussed specifically pertain to epilepsy, similar connections can be drawn with other chronic paediatric conditions such as diabetes and asthma., ${ }^{5,37,38}$ However, children with epilepsy can, to an extent, "hide" their epilepsy from friends to maintain their "normality" to others; this is not possible with conditions such as asthma where disclosure is inevitable. There are similarities in response to diagnosis for children and parents, but there are also differences.

Children do not experience illness and its care alone; parents also experience ramifications and manage their children's psychosocial needs as well as their own in the process, as both move towards a new family life that incorporates it. Having an awareness of how a diagnosis can be perceived by the child, family, and wider social circles will ensure that children with epilepsy and their families can be fully supported by healthcare professionals throughout the course of the illness and its treatment. Key challenges to working with paediatric populations highlight the need to recognize children's autonomy and agency, to engage in effective communication, and to understand their wider contexts of family life.

\section{REFERENCES}

1. General Medical Council. Tomorrow's Doctors: Recommendations on Undergraduate Medical Education. London, UK: General Medical Council; 2003.

\section{Frenk J, Chen L, Bhutta ZA, Cohen J, Crisp N,}

Evans T, et al. Health professionals for a new century: transforming education to strengthen health systems in an interdependent world. Lancet. 2010;76(9756):192358. DOI: 10.1016/S0140-6736(10)61854-5.

3. Litva A, Peters S. Exploring barriers to teaching behavioural and social sciences in medical education. 
Med Educ. 2008;42:309-14. DOI: 10.1111/j.13652923.2007.02951.x.

4. Brady G, Lowe P, Olin Lauritzen S. Connecting a sociology of childhood perspective with the study of child health, illness and wellbeing: introduction. Sociol Health Illn. 2015;37(2):173-83. DOI: 10.1111/14679566.12260 .

5. Koller D, Khan N, Barrett S. Pediatric perspectives on diabetes self-care: A process of achieving acceptance. Qual Health Res. 2015;25(2):264-75. DOI: $10.1177 / 1049732314551057$.

\section{Moffat C, Dorris L, Connor L, Espie CA. The} impact of childhood epilepsy on quality of life: a qualitative investigation using focus group methods to obtain children's perspectives on living with epilepsy. Epilepsy Behav. 2009;14(1):179-89. DOI: 10.1016/j.yebeh.2008.09.025.

7. Mayall B. Towards a sociology of child health. Sociol Health Illn. 1998;20(3):269-88.

8. General Assembly of the United Nations. Convention on the Rights of the Child. General Assembly Resolution 44/25 of 20 November 1989. Geneva, Switzerland: Office of the High Commissioner for Human Rights; 1989.

9. Appleton R, Marson A. Epilepsy: The Facts. 3rd edition. Oxford, UK: Oxford University Press; 2009.

10. Ronen GM, Streiner DL, Verhey LH, Lach L, Boyle MH, Cunningham CE, et al. Disease characteristics and psychosocial factors: explaining the expression of quality of life in childhood epilepsy. Epilepsy Behav. 2010;18(1-2):88-93. DOI: 10.1016/j.yebeh.2010.02.023.

11. Speechley KN, Ferro MA, Camfield CS, Huang W, Levin SD, Smith ML, et al. Quality of life in children with new-onset epilepsy: a 2-year prospective cohort study. Neurology. 2012;79(15):1548-55. DOI:

0.1212/WNL.0b013e31826e25aa.
12. Harden J, Black R, Chin RF. Families' experiences of living with pediatric epilepsy: a qualitative systematic review. Epilepsy Behav. 2016;60:225-37. DOI: 10.1016/j.yebeh.2016.04.034.

13. Aaberg KM, Bakken IJ, Lossius MI, Lund Søraas C, Håberg SE, Stoltenberg C, et al. Comorbidity and childhood epilepsy: a nationwide registry study.

Pediatrics. 2016;138(3):1-12. DOI:

10.1542/peds.2016-0921.

14. Eklund PG, Sivberg, B. Adolescents' lived experience of epilepsy. J Neurosci Nurs.

2003;35(1):40-9.

15. Elliott IM, Lach L, Smith ML. I just want to be normal: a qualitative study exploring how children and adolescents view the impact of intractable epilepsy on their quality of life. Epilepsy Behav. 2005;7(4):66478. DOI: 10.1016/j.yebeh.2005.07.004.

16. McEwan MJ, Espie CA, Metcalfe J. A systematic review of the contribution of qualitative research to the study of quality of life in children and adolescents with epilepsy. Seizure. 2004;13(1):3-14. DOI:

10.1016/S1059-1311(03)00081-5.

17. Galletti F, Rinna A, Acquafondata C. An insight into children's and adolescents' experience of seizures and epilepsy. Seizure. 1998;7(4):309-16. DOI: 10.1016/S1059-1311(98)80024-1.

18. Reilly C, Atkinson P, Das KB, Chin RF, Aylett SE, Burch V, et al. Neurobehavioural comorbidities in children with active epilepsy: a population-based study. Pediatrics. 2014;133(6):e1586-93. DOI: 10.1542/peds.2013-3787.

19. Carson J, Weir A, Chin RF, McLellan A. Socioeconomic deprivation is an independent risk factor for behavioral problems in children with epilepsy. Epilepsy Behav. 2015;45:105-9. DOI: 10.1016/j.yebeh.2015.03.009.

20. Hightower S, Carmon M, Minick P. A qualitative descriptive study of the lived experiences of school- 
aged children with epilepsy. J Pediatr Health Care. 2002;16(3):131-7. DOI: 10.1067/mph.2002.119599.

21. Lewis A, Parsons S. Understanding of epilepsy by children and young people with epilepsy. Eur J Spec Needs Educ. 2008;23(4):321-35.

10.1080/08856250802387273.

22. Barker DJ. The fetal and infant origins of adult disease. BMJ. 1990;301(6761):1111.

23. Chin RF, Cumberland PM, Pujar SS, Peckham C, Ross EM, Scott RC. Outcomes of childhood epilepsy at age 33 years: a population-based birth-cohort study. Epilepsia. 2011;52(8):1513-21. DOI: 10.1111/j.15281167.2011.03170.x.

24. Bury M. The sociology of chronic illness: a review of research and prospects. Sociol Health Illn. 1991;13(4):451-68. DOI: 10.1111/j.14679566.1991.tb00522.x.

25. Nettleton S. The Sociology of Health and Illness. Cambridge, UK: Polity; 2013.

26. Smith G, Wagner J, Andrews J, Austin J, Mueller M, Carter E, et al. Caregiving in pediatric epilepsy: results of focus groups and implications for research and practice. Epilepsy Behav. 2014;34:34-41. DOI: 10.1016/j.yebeh.2014.03.002.

27. Williams S. Chronic illness as biographical disruption or biographical disruption as chronic illness? Reflections on a core concept. Sociol Health Illn. 2000;22(1):40-67. DOI: 10.1111/14679566.00191 .

28. Mu PF. Transition experience of parents caring of children with epilepsy: a phenomenological study. Int J Nurs Stud. 2008;45(4):543-51. DOI:

10.1016/j.jpurstu.2006.10.009.

29. Bray L, Kirk S, Callery P. Developing biographies: the experiences of children, young people and their parents of living with a long-term condition. Sociol Health Illn. 2014;36(6):823-39. DOI: 10.1111/14679566.
30. Curtis-Tyler K. Facilitating children's contributions in clinic? Findings from an in-depth qualitative study with children with Type 1 diabetes. Diabet Med. 2012;29(10):1303-10. DOI: 10.1111/j.1464-5491.2012.03714.x.

\section{Alderson P, Sutcliffe K, Curtis K. Children as} partners with adults in their medical care. Arch Dis Child. 2006;91(4):300-3. DOI:

10.1136/adc.2005.079442.

32. Thorne S, Paterson B, Russell C. The structure of everyday self-care decision making in chronic illness. Qual Health Res. 2003;13(10):1337-52. DOI: $10.1177 / 1049732303258039$.

33. Alderson P. Children's Consent to Surgery. Buckingham, UK: Open University Press; 1993.

34. Coyne I. Consultation with children in hospital: children, parents' and nurses' perspectives. J Clin Nurs. 2006;15(1):61-71. DOI: 10.1111/j.13652702.2005.01247.x.

35. LeFrancois BA. Children's participation rights: voicing opinions in inpatient care. Child Adolesc Ment Health. 2007;12(2):94-7. DOI: 10.1111/j.14753588.2007.00439.x.

36. Tates K, Meeuwesen L. Doctor-patient-child communication. A (re)view of the literature. Soc Sci Med. 2001;52(6):839-51. DOI: 10.1016/S02779536(00)00193-3.

37. Amer KS. Children's views of their adaptation to type 1 diabetes mellitus. Pediatr Nurs. 2008;34(4):28191.

38. Callery P, Milnes L, Verduyn C, Couriel J. Qualitative study of young people's and parents' beliefs about childhood asthma. Br J Gen Pract. 2003;53(488):185-90. 